\title{
Characteristics and outcome of patients with low-/intermediate-risk acute promyelocytic leukemia treated with arsenic trioxide: an international collaborative study
}

Haematologica 2021

Volume 106(12):3100-3106

Presented in part at the 21st Annual Meeting of the European Hematology Association in Frankfurt, Germany, June 10th, 2020.

\section{Correspondence:}

SABINE KAYSER

sabine.kayser@medizin.uni-leipzig.de

Received: March 6, 2021.

Accepted: April 26, 2021.

Pre-published: May 27, 2021.

https://doi.org/10.3324/haematol.2021.278722

\section{(C2021 Ferrata Storti Foundation}

Material published in Haematologica is covered by copyright. All rights are reserved to the Ferrata Storti Foundation. Use of published material is allowed under the following terms and conditions:

https://creativecommons.org/licenses/by-nc/4.0/legalcode. Copies of published material are allowed for personal or internal use. Sharing published material for non-commercial purposes is subject to the following conditions:

https://creativecommons.org/licenses/by-nc/4.0/legalcode, sect. 3. Reproducing and sharing published material for commercial purposes is not allowed without permission in writing from the publisher.
Sabine Kayser, ${ }^{1,2}$ Richard F. Schlenk, ${ }^{2,3}$ Delphine Lebon, ${ }^{4}$ Martin Carre, ${ }^{5}$ Katharina

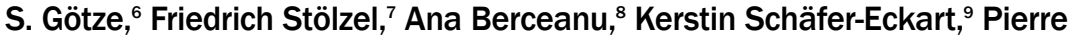
Peterlin, ${ }^{10}$ Yosr Hicheri, ${ }^{11}$ Ramy Rahmé, ${ }^{12}$ Emmanuel Raffoux, ${ }^{12}$ Fatiha Chermat, ${ }^{12}$ Stefan W. Krause, ${ }^{13}$ Walter E. Aulitzky, ${ }^{14}$ Sophie Rigaudeau, ${ }^{15}$ Richard Noppeney, ${ }^{16}$ Celine Berthon, ${ }^{17}$ Martin Görner, ${ }^{18}$ Edgar Jost, ${ }^{19}$ Philippe Carassou, ${ }^{20}$ Ulrich Keller, ${ }^{21}$ Corentin Orvain, ${ }^{22,23,24}$ Thorsten Braun, ${ }^{25}$ Colombe Saillard, ${ }^{26}$ Ali Arar, ${ }^{27}$ Volker Kunzmann, ${ }^{28}$ Mathieu Wemeau, ${ }^{29}$ Maike de Wit, ${ }^{30}$ Dirk Niemann, ${ }^{31}$ Caroline Bonmati, ${ }^{32}$ Carsten Schwänen, ${ }^{33}$ Julie Abraham, ${ }^{34}$ Ahmad Aljijakli, ${ }^{35}$ Stéphanie Haiat, ${ }^{36}$ Alwin Krämer, ${ }^{37,38}$ Albrecht Reichle, ${ }^{39}$ Martina Gnadler, ${ }^{40}$ Christophe Willekens, ${ }^{41,42}$ Karsten Spiekermann, ${ }^{43}$ Wolfgang Hiddemann, ${ }^{43}$ Carsten Müller-Tidow, ${ }^{37}$ Christian Thiede, ${ }^{7}$ Christoph Röllig, ${ }^{7}$ Hubert Serve, ${ }^{44}$ Martin Bornhäuser, ${ }^{7}$ Claudia D. Baldus, ${ }^{45}$ Eva Lengfelder, ${ }^{46}$ Pierre Fenaux, ${ }^{12}$ Uwe Platzbecker ${ }^{1 \#}$ and Lionel Adès ${ }^{12 \#}$

${ }^{1}$ Medical Clinic and Policlinic I, Hematology and Cellular Therapy, University Hospital Leipzig, Leipzig, Germany; ${ }^{2}$ NCT Trial Center, National Center of Tumor Diseases, German Cancer Research Center (DKFZ), Heidelberg, Germany; ${ }^{3}$ Department of Internal Medicine V, Heidelberg University Hospital, Heidelberg, Germany ${ }^{4}$ Service des Maladies du Sang GH Sud, Amiens, France; ${ }^{5} \mathrm{HCE}$ Grenoble, Service d'Oncologie et Hématologie Pédiatrique, Grenoble, France; ${ }^{6}$ Department of Medicine III, Technical University of Munich, Munich, Germany; ${ }^{7}$ Department of Medicine I, University Hospital Carl-Gustav-Carus, Dresden, TU Dresden, Germany; ${ }^{8}$ Service d'Hématologie du Pr. Cahn Hopital Jean Minjoz, Besancon, France; ${ }^{~} \mathrm{Hospital}$ Nord, Nurnberg, Germany; ${ }^{10}$ Service d'Hématologie, Hotel Dieu Nantes, France; ${ }^{11}$ Département d'Hématologie Clinique du Chu Saint Eloi Montpellier, Montpellier, France; ${ }^{12} \mathrm{Hôp}$ ital Saint Louis, Université Paris Diderot, Paris, France; ${ }^{13}$ Department of Internal Medicine 5 - Hematology/Oncology, University Hospital of Erlangen, Erlangen, Germany; ${ }^{14}$ Robert-Bosch-Hospital, Stuttgart, Germany; ${ }^{15}$ Service d'Hémato-Oncologie du Pr. Castaigne Hopital Andre Mignot le Chesnay, Versailles, France; ${ }^{16}$ University Hospital Essen, Essen, Germany; ${ }^{17}$ Service des Maladies du Sang Chru, Hopital Claude Huriez, Lille, France; ${ }^{18} \mathrm{Klinik}$ für Hämatologie, Onkologie und Palliativmedizin, Klinikum Bielefeld Mitte, Bielefeld, Germany; ${ }^{19}$ University Hospital Aachen, Aachen, Germany; ${ }^{20}$ Department of Hematology, Centre Hospitalier Régional (CHR) Metz-Thionville, Metz, France; ${ }^{21}$ Department of Hematology, Oncology and Tumor Immunology, Charité-University Medical Center, Campus Benjamin Franklin, Berlin, Germany; ${ }^{22}$ Angers University Hospital, Maladies du Sang, Angers, France; ${ }^{23}$ Fédération Hospitalo-Universitaire Grand-Ouest Acute Leukemia, FHU-GOAL, France; ${ }^{24}$ Université d'Angers, INSERM, CRCINA, Angers, France; ${ }^{25} \mathrm{Hôpital}$ Avicenne, Assistance Publique - Hôpitaux de Paris, Université Paris 13, Bobigny, France; ${ }^{26} \mathrm{Hematology}$ Department, Institut Paoli Calmettes, Marseille, France; ${ }^{27}$ Service d' Oncologie Médicale Hopital de la Source, Orleans, France; ${ }^{28}$ University Hospital of Würzburg, Würzburg, Germany; ${ }^{29}$ Service d'Hématologie, Hopital V. Provo, Roubaix, France; ${ }^{30}$ Vivantes Klinikum Neukölln, Berlin, Germany; ${ }^{31}$ Gemeinschaftsklinikum Mittelrhein gGmbH, Koblenz, Germany; ${ }^{32}$ Division of Hematology, Hôpital de Brabois, Centre Hospitalier Universitaire de Nancy, Nancy, France; ${ }^{33}$ Klinikum Offenburg, Offenburg, Germany; ${ }^{34}$ Service d' Hématologie, Thérapie Cellulaire du Pr. Bordessoule, Hopital Universitaire Dupuytren, Limoges, France; ${ }^{35}$ Service d'Hématologie du Dr. Sutton Centre Hospitalier v. Dupouy, Argenteuil, France; ${ }^{36}$ Service d'Hematologie Clinique, CH Sud Francilien, Corbeil Essonnes, France; ${ }^{37}$ Department of Internal Medicine V, University Hospital of Heidelberg, Heidelberg, Germany; ${ }^{38}$ German Cancer Research Center (DKFZ) and Department of Internal Medicine V, University of Heidelberg, Heidelberg, Germany; ${ }^{39}$ Department of Medicine III - Hematology and Internal Oncology, University Hospital Regensburg, Regensburg, Germany; ${ }^{40}$ St. Vincentius Kliniken, Abteilung für Hämatologie, Onkologie, Immunologie und Palliativmedizin, Karlsruhe, Germany; ${ }^{41}$ Département d'Hématologie, Gustave Roussy, Université Paris-Saclay, Villejuif, France; ${ }^{42}$ INSERM Unit 1287, Gustave Roussy Cancer Campus, Paris-Saclay University, Villejuif, France; ${ }^{43}$ Department of Medicine III, University Hospital, Ludwig-Maximilians University (LMU) Munich, Munich, Germany; ${ }^{44}$ Department of Internal Medicine II, University Hospital of Frankfurt am Main, Germany; ${ }^{45}$ Department of Internal Medicine II, University Hospital of Kiel, Kiel, Germany and ${ }^{46}$ Department of Hematology and Oncology, University Hospital Mannheim, Mannheim, Germany.

"UP and LA contributed equally as co-senior authors. 
T he aim of this study was to characterize a large series of 154 patients with acute promyelocytic leukemia (median age, 53 years; range, 18-90 years) and evaluate real-life outcome after up-front treatment with arsenic trioxide and all-trans retinoic acid. All patients were included in the prospective NAPOLEON registry (NCT02192619) between 2013 and 2019. The acute promyelocytic leukemia was de novo in $91 \%(n=140)$ and therapy-related in $9 \%(n=14) ; 13 \%(n=20)$ of the patients were older than 70 years. At diagnosis bleeding/hemorrhage was present in 38\% and thrombosis in 3\%. Complete remission was achieved in 152 patients (99\%), whereas two patients (1\%) experienced induction death within 18 days after starting therapy. With a median follow-up of 1.99 years (95\% confidence interval: 1.61-2.30 years) 1-year and 2-year overall survival rates were 97\% (95\% confidence interval: $94-100 \%$ ) and $95 \%$ (95\% confidence interval: $91-99 \%$ ), respectively. Age above 70 years was associated with a significantly shorter overall survival $(P<0.001)$ compared to that of younger patients. So far no relapses have been observed. Six patients (4\%) died in complete remission at a median of 0.95 years after diagnosis (range, 0.18-2.38 years). Our data confirm the efficiency and durability of arsenic trioxide and all-trans retinoic acid therapy in the primary management of adults with low-/intermediate-risk acute promyelocytic leukemia in the real-life setting, irrespective of age.

\section{Introduction}

Acute promyelocytic leukemia (APL), characterized by the balanced translocation $\mathrm{t}(15 ; 17)$ (q22;q12) resulting in the fusion transcript PML-RARA, is a rare entity of acute myeloid leukemia, accounting for roughly $5-8 \%$ of cases of acute myeloid leukemia. ${ }^{1}$ With the introduction of all-trans retinoic acid (ATRA) and arsenic trioxide (ATO), the prognosis of APL has been transformed and this is now one of the most curable malignant diseases.

Published data from a large multicenter phase III randomized trial (APL0406) on a direct comparison of ATO/ATRA versus ATRA in combination with idarubicin (AIDA) or mitoxantrone in adult patients with de novo, low-/intermediate-risk APL showed very promising results in favor of ATO/ATRA, with a 2-year event-free survival rate of $97 \%$ versus $86 \%(P=0.02){ }^{2}$ Within this trial, the early mortality rate as well as hematologic toxicities were significantly lower in patients treated with ATO/ATRA than in those treated with AIDA. In particular, the cumulative incidence of relapse after 50 months was only $1.9 \%$ after ATO/ATRA as compared to $13.9 \%$ after chemotherapy and ATRA. ${ }^{3}$ Moreover, none of the patients treated with ATO/ATRA developed a therapy-related myeloid neoplasm as compared to two patients in the chemotherapy/ATRA arm. ${ }^{3}$ Another Medical Research Council publication supported these results, with a 4-year event-free survival rate of $91 \%$ after ATO/ATRA as compared to $70 \%$ after chemotherapy and ATRA $(P=0.002){ }^{4}$ The ATO/ATRA regimen was, however, associated with a higher frequency of grade 3 or 4 hepatic toxicity $(44 \%$ vs. $3 \% ; P<0.001)$. In all cases, toxic effects resolved with temporary discontinuation of ATO and/or ATRA ${ }^{3}$ and the chemotherapy-free regimen with ATO/ATRA has become standard first-line therapy in low/intermediate-risk de novo APL. However, apart from reports of the randomized Italian-German APL0406, $6^{2,3}$ and the AML17 trials, ${ }^{4}$ data on outcomes after up-front treatment with ATO/ATRA in the real-world setting are scarce.

Previously published data from registries and populationbased studies indicated that outcomes of patients with APL were inferior to those reported in clinical trials, mainly due to higher early death rates. ${ }^{5.8}$ However, none of these studies included results after treatment with ATO/ATRA. Recently published results from the randomized Italian-
German APL0406 trial suggest, albeit within the context of highly selected patients and closely monitored therapy, that treatment with ATO/ATRA can reduce early deaths and improve long-term outcomes.,3 Whether or not these results can be replicated in population-based settings is currently unclear.

The objectives of our study were to characterize a large series of APL patients included in the prospective NAPOLEON registry and evaluate their outcome after upfront treatment with ATO/ATRA.

\section{Methods}

\section{Patients and treatment}

Data on 167 APL patients, reported within the NAPOLEON registry (ClinicalTrials.gov Identifier: NCT02192619) between 2013 and 2019 within two large European study groups (APL French group, $n=89$; Study Alliance Leukemia, n=78) were collected. This real-life registry included data on patients' demographics, treatment, response, severe adverse events and follow-up. There were no criteria for exclusion of APL patients from this registry. However, for the current analysis the inclusion criterion was treatment with ATO/ATRA and exclusion criteria were age below 18 years $(n=6)$, high-risk APL (white blood cell [WBC] count $>10 \times 10^{9} / \mathrm{L}$, at diagnosis, $\mathrm{n}=4$ ) and lack of data on WBC count $(n=3)$. The final study cohort consisted of 154 patients. Ideally, patients were included within the same $(n=45)$ or following $(n=32)$ day of APL diagnosis. Additionally 46 patients were included within the first 8 days after diagnosis (overall $n=123 ; 80 \%$ ), when the risk of early death is highest. ${ }^{8}$ Outcome was calculated using the date of initial diagnosis. None of the patients was treated within a clinical trial.

The diagnosis of APL was based on genetic analysis as well as on French-American-British Cooperative Group criteria, ${ }^{9}$ and, after 2003, on revised International Working Group criteria. ${ }^{10}$ Chromosome banding analysis was performed using standard techniques, and karyotypes were described according to the International System for Human Cytogenetic Nomenclature. ${ }^{11}$ The diagnosis was confirmed by either reverse-transcriptase polymerase chain reaction (RT-PCR) or fluorescence in-situ hybridization (FISH) detection by standard methods. FLT3 mutation screening for internal tandem duplications (ITD) and point mutations within the tyrosine kinase domain was carried out as previously 
described. ${ }^{12,13}$ Data collection and analysis were approved by the local Institutional Review Boards.

\section{Treatment}

All patients were treated with ATO/ATRA as induction therapy and with up to four consolidation cycles of ATO/ATRA. ${ }^{2}$ Eight patients additionally received $12 \mathrm{mg} / \mathrm{m}^{2}$ idarubicin (for up to 4 days) and two patients received $100 \mathrm{mg} / \mathrm{m}^{2}$ cytarabine for up to 2 days during induction with ATO/ATRA because of WBC counts rising above $10 \times 10^{9} / \mathrm{L}$. One elderly patient (age, 72 years) was initially treated with decitabine ( $38 \mathrm{mg} /$ day) for 5 days and was then switched to two cycles of ATO/ATRA after genetic analysis revealed $t(15 ; 17)$. Response was assessed according to Cheson et al. ${ }^{10}$

\section{Statistical analyses}

Survival endpoints including overall survival and cumulative incidence of death in complete remission were defined according to the revised recommendations of the International Working Group. ${ }^{10}$ Induction death was defined as death occurring at any time during induction therapy before the achievement of complete remission. Comparisons of patients' characteristics were performed with the Kruskal-Wallis rank sum test for continuous variables and Fisher exact test for categorical variables. The median follow-up time was computed using the reverse Kaplan-Meier estimate. ${ }^{14}$ The Kaplan-Meier method was used to estimate the distribution of overall survival. ${ }^{15}$ Confidence interval (CI) estimates for survival curves were based on the cumulative hazard function using the Greenwood formula for variance estimation. Log-rank tests were employed to compare survival curves between groups. The cumulative incidence of death in complete remission and the standard error were computed using the method described by Gray $^{16}$ and included only patients attaining complete remission. All statistical analyses were performed with the statistical software environment $\mathrm{R}$, version 3.3.1, using the $\mathrm{R}$ packages, and survival, version $2.39-5 .^{17}$

\section{Results}

In total, data on 154 low-/intermediate-risk APL patients, reported within the NAPOLEON registry between 2013 and 2019 within two large European study groups were included. The median age of these patients was 53 years (range, $18-90$ years); $13 \%(n=20)$ were older than 70 years. APL was de novo in $91 \%(n=140)$ and therapy-related in $9 \%$ $(n=14)$. Primary malignancies included solid cancers in 12 patients (breast cancer, $\mathrm{n}=5$; female genital tract, $\mathrm{n}=2$; prostate cancer, lung cancer, colon cancer, intraabdominal liposarcoma, and epidermoid cancer, $n=1$ each) and lymphoma in two patients. All patients received chemotherapy and/or radiation as treatment for the prior malignancy/neoplasm and were in remission at the time of APL diagnosis. The median latency period between diagnosis of the primary malignancy/neoplasm and the occurrence of therapyrelated APL was 2.80 years (range, 1.68-7.70 years).

Information on extramedullary disease was available for 131 patients and was present in two $(1.5 \%)$ patients (skin manifestation, hepatosplenomegaly; $n=1$ each). Comorbidities were present in $48(58 \%)$ of 83 patients and included arterial hypertension $(n=25)$, pulmonary disease $(\mathrm{n}=12$; mild, $\mathrm{n}=5$, moderate/severe, $\mathrm{n}=7$ ), gastro-intestinal disease $(n=9)$, renal disease $(n=8 ;$ mild, $n=4$, moderate/severe, $n=4)$, diabetes $(n=8)$, psychiatric disturbance $(n=8)$, cardiac/arrhythmias $(n=6)$, rheumatologic dis- order $(n=5)$, hepatic disease $(n=3$, mild, $n=1$, moderate/severe, $n=2)$, cerebrovascular disease $(n=3)$, and immunosuppression due to human immune-deficiency virus infection $(\mathrm{n}=2)$.

In all patients APL was confirmed by cytogenetics and/or FISH/RT-PCR. Information on cytogenetics was available for $132(86 \%)$ patients. In seven $(5 \%)$ patients $t(15 ; 17)$ could only be detected by FISH and/or RT-PCR, while cytogenetics showed a normal karyotype. In 82 (66\%) of the remaining 125 patients, the balanced $\mathrm{t}(15 ; 17)$ translocation was the sole abnormality, whereas in $43(34 \%)$ patients, the translocation was accompanied by additional cytogenetic abnormalities, most frequently $\mathrm{t}(15 ; 17)$ within a complex karyotype, i.e., $\geq 2$ cytogenetic abnormalities in addition to $\mathrm{t}(15 ; 17)(\mathrm{n}=16)$ or trisomy $8(\mathrm{n}=7)$.

Regarding FLT3-ITD mutational status, information was available for 51 (33\%) of the 154 patients. Of those, eight (16\%) patients were FLT3-ITD-positive. Information on the $P M L-R A R A$ transcript isoform (breakpoint cluster region, BCR) was available for 104 (67\%) patients and 50 had the short isoform (BCR3). The patients' baseline characteristics are shown in Table 1.

\section{Response to induction therapy}

Overall, 152 patients (99\%) achieved complete remission, whereas two patients (1\%) experienced induction death within 18 days after starting therapy due to acute respiratory failure with bilateral pneumonia in one case and ischemic cardiomyopathy in the other. Both patients had de novo APL, Eastern Cooperative Oncology Group performance status $\leq 2$ and no signs of hemorrhage or thrombosis at initial presentation. They were 64 and 75 years old. Cytogenetics in both cases revealed $t(15 ; 17)$ as the sole abnormality; no concurrent FLT3-ITD was present.

None of the patients was refractory to treatment. In univariable analysis age above 70 years had no impact on response to induction therapy $(P=0.24)$.

\section{Survival analysis}

The median follow-up for survival was 2 years $(95 \% \mathrm{CI}$ : 1.61-2.30 years). Overall, the estimated 1 -year and 2 -year overall survival rates were 97\% (95\% CI: $94-100 \%)$ and 95\% (95\% CI: 91-99\%), respectively (Figure 1). The overall survival rate was significantly lower in elderly patients $(>70$ years) than in younger patients $(P<0.001)$ (Figure 2$)$.

None of the patients relapsed after ATO/ATRA treatment, thus overall survival and event-free survival were identical. Six (4\%) patients died in remission at a median of 0.95 years after diagnosis (range, $0.18-2.38$ years). Of these patients, three were below 70 years old. Causes of death were sepsis $(n=2)$, bleeding/hemorrhage $(n=1)$, pulmonary edema due to tachycardic atrial fibrillation $(n=1)$, progress of an underlying intra-abdominal liposarcoma $(n=1)$ as well as hepato-renal syndrome $(n=1)$. The cumulative incidence of death in complete remission was significantly higher in older patients than in younger patients $(P=0.001)$ (Figure 3$)$. So far, none of the patients has developed a secondary neoplasm after treatment with ATO/ATRA.

\section{Toxicity}

A total of 118 serious adverse events were reported in 60 patients, mainly infections $(n=31)$, hepatobiliary events $(\mathrm{n}=21)$, neurotoxicity/neuropathy $(\mathrm{n}=9$, including headache in 2 patients), and cardiac events ( $n=6$, including QTc prolongation in 2 patients). Serious adverse events classified as 
related to differentiation syndrome were reported in seven patients. As prophylaxis for the differentiation syndrome prednisone at a dose of $0.5 \mathrm{mg} / \mathrm{kg}$ of body weight per day was administered from day 1 until the end of induction therapy. ${ }^{2}$ Toxicities are listed in Table 2. Due to the adverse event, ATRA was withdrawn in five patients, and restarted in four, requiring a dose reduction to $50 \%$ in one of the patients. ATO was withdrawn in two patients, and restarted in one; additionally, three patients had dose reductions. Most of the patients recovered from the serious adverse events $(n=52)$, although eight patients died. Of the eight fatal serious adverse events, two occurred during induction within 18 days (acute respiratory failure with bilateral pneumonia, $\mathrm{n}=1$; and ischemic cardiomyopathy, $\mathrm{n}=1$ ) and six occurred in complete remission (infection/sepsis, $\mathrm{n}=2$, bleeding/hemorrhage, $\mathrm{n}=1$; pulmonary edema due to tachycardic atrial fibrillation $n=1$; progress of an underlying intraabdominal liposarcoma $\mathrm{n}=1$, and hepato-renal syndrome $\mathrm{n}=1$ ).

\section{Discussion}

This is the largest real-life data analysis of first-line ATO/ATRA treatment in a prospective registry in low/intermediate-risk APL patients. It confirms a very high response rate as well as excellent overall survival with this new standard of care.,3 Our data confirm that results can be replicated in a clinical registry, even within the context of non-selected patients and less closely monitored therapy than in the pivotal study. Indeed, on the basis of our registry data, the outcome of patients was identical to that reported after treatment with ATO/ATRA within the APL0406 trial. ${ }^{2,3}$ In contrast, the outcome of APL patients from previously published registries or population-based studies was inferior to that reported in clinical trials, mainly because of higher early death rates.5.8 However, these registries and population-based studies included results before treatment with ATO/ATRA had been approved by regulatory authorities. $^{5.8}$

In our cohort the rate of induction death was extremely low, which might be in part attributable to improved supportive care and awareness of APL as a medical emergency, ${ }^{18}$ but also to early treatment with ATO/ATRA itself. Thus, effective strategies due to standardized guidelines along with consultative support and sharing of expertise seem to be well-taken and overcome induction mortality. ${ }^{19}$ Only two patients died during induction, in one case due to ischemic cardiomyopathy and in the other acute respiratory failure as a result of bilateral pneumonia. More impressively, none of the patients experienced induction death due to bleeding/hemorrhage or infections, which is in sharp contrast to previously published data on AIDA-based treatment. ${ }^{20,21}$ Nevertheless, we cannot rule out a potential selection bias since patients may also die before diagnosis. Highrisk APL (WBC count $>10 \times 10^{9} / \mathrm{L}$ ) at diagnosis is a known risk-factor for a bleeding diathesis. ${ }^{22}$ The European randomized intergroup study "APOLLO" is currently investigating idarubicin $12 \mathrm{mg} / \mathrm{m}^{2}$ on days 1 and 3 in addition to oral ATRA $45 \mathrm{mg} / \mathrm{m}^{2}$ twice daily on days $1-28$ and ATO 0.15 $\mathrm{mg} / \mathrm{kg} /$ day intravenously on days 5-28 followed by four cycles of ATO/ATRA consolidation therapy as compared to the standard chemotherapy/ATRA approach (ClinicalTrails.gov identifier: NCT02688140).

The induction death rate in our analysis even compares favorably with the recently published data from the Swedish Acute Leukemia Registry, which recorded an early death rate of $15 \%$ in newly diagnosed, low-/intermediaterisk APL $(n=65)$ for the observation period 2009-2013. ${ }^{\circ}$ Thus, early treatment with ATO/ATRA seems to tackle the threat of induction death, again confirming recently pub-

Table 1. Characteristics of the 154 patients with acute promyelocytic leukemia at diagnosis.

\begin{tabular}{|c|c|c|}
\hline & $\mathrm{N}=154$ & $\%$ \\
\hline Gender: female & 75 & 49 \\
\hline $\begin{array}{l}\text { Type of APL } \\
\text { De novo } \\
\text { Therapy-related }\end{array}$ & $\begin{array}{c}140 \\
14\end{array}$ & $\begin{array}{c}91 \\
9\end{array}$ \\
\hline $\begin{array}{l}\text { ECOG performance status } \\
0 \\
1 \\
2 \\
3 \\
4 \\
\text { Missing }\end{array}$ & $\begin{array}{c}42 \\
84 \\
9 \\
3 \\
3 \\
13\end{array}$ & $\begin{array}{c}27 \\
55 \\
6 \\
2 \\
2 \\
8\end{array}$ \\
\hline $\begin{array}{l}\text { Bleeding/hemorrhage } \\
\text { Overall } \\
\text { Skin } \\
\text { CNS bleeding } \\
\text { Pulmonary } \\
\text { Missing }\end{array}$ & $\begin{array}{c}59 \\
32 \\
3 \\
1 \\
1\end{array}$ & $\begin{array}{c}38 \\
21 \\
2 \\
1 \\
1\end{array}$ \\
\hline $\begin{array}{l}\text { Thrombosis } \\
\text { Missing }\end{array}$ & $\begin{array}{l}5 \\
5\end{array}$ & $\begin{array}{l}3 \\
3\end{array}$ \\
\hline $\begin{array}{l}\text { BCR1/2 } \\
\text { BCR3 } \\
\text { Missing }\end{array}$ & $\begin{array}{l}54 \\
50 \\
50\end{array}$ & $\begin{array}{l}35 \\
32 \\
32\end{array}$ \\
\hline $\begin{array}{l}\text { Cytogenetics } \\
\text { Normal } \\
\text { Sole abnormality } \\
\text { Additional abnormalities } \\
\text { - Complex* } \\
\text { - Trisomy 8 } \\
\text { Missing }\end{array}$ & $\begin{array}{c}7 \\
82 \\
43 \\
16 / 43 \\
7 / 43 \\
22\end{array}$ & $\begin{array}{c}5 \\
53 \\
28 \\
37 \\
16 \\
14\end{array}$ \\
\hline $\begin{array}{l}\text { FLT3-ITD positive } \\
\text { Missing }\end{array}$ & $\begin{array}{l}8 / 51 \\
103\end{array}$ & $\begin{array}{l}16 \\
67\end{array}$ \\
\hline $\begin{array}{l}\text { FAB subtype } \\
\text { M3 } \\
\text { M3v } \\
\text { Missing }\end{array}$ & $\begin{array}{c}138 \\
7 \\
9\end{array}$ & $\begin{array}{c}90 \\
5 \\
6\end{array}$ \\
\hline & Value & Range \\
\hline Median ITD allelic ratio & 0.113 & $0.01-63$ \\
\hline $\begin{array}{l}\text { Median age, years } \\
\text { N. }>70 \text { years }\end{array}$ & $\begin{array}{l}53 \\
20\end{array}$ & $\begin{array}{c}18-90 \\
13 \%\end{array}$ \\
\hline Median WBC, x $10^{9} / \mathrm{L}$ & 1.2 & $0.2-10$ \\
\hline Median platelets x $10^{9} / \mathrm{L}$ & 41 & $2-210$ \\
\hline $\begin{array}{l}\text { Median hemoglobin, } \mathrm{g} / \mathrm{dL} \\
\text { Missing }\end{array}$ & $\begin{array}{c}10 \\
1\end{array}$ & $3.5-14.8$ \\
\hline $\begin{array}{l}\text { Median BM blasts, }{ }^{* *} \% \\
\text { Missing }\end{array}$ & $\begin{array}{l}65 \\
23 \\
\end{array}$ & $0-95$ \\
\hline $\begin{array}{l}\text { Median creatinine, mg/dL } \\
\text { Missing }\end{array}$ & $\begin{array}{c}0.88 \\
8\end{array}$ & $0.49-8.14$ \\
\hline
\end{tabular}

APL; acute promyelocytic leukemia; ECOG: Eastern Cooperative Oncology Group; CNS: central nervous system; BCR, breakpoint cluster region; ITD: internal tandem duplication; FAB: French American British;WBC: white blood cell counts; BM: bone marrow. Percentages may not add to 100 because of rounding. *Two or more cytogenetic abnormalities in addition to $\mathrm{t}(15 ; 17)$; ** Blast cells included malignant promyelocytes. Percentages may not sum up to 100 due to rounding. 
lished results on ATO/ATRA from the randomized ItalianGerman APL0406 trial., ${ }^{2,3}$ However, part of the difference may be explained by the fact that the Swedish report contained data from a population-based registry, whereas for our data, selective reporting cannot be ruled out. The underlying patho-mechanism by which ATO in combination with ATRA exerts this effect remains elusive. The transcription factor $P M L-R A R A$ behaves as an altered retinoic acid receptor with the ability to transmit oncogenic signals leading to accumulation of undifferentiated promyelocytes. ${ }^{23}$ ATRA induces disease remission in APL patients by triggering terminal differentiation of leukemic promyelocytes. In addition, ATO has been shown to contribute to degradation of the PML-RARA oncoprotein through binding the PML moiety. ${ }^{23,24}$

Regarding post-remission outcome, results of the randomized North American Leukemia Intergroup Study C9710 on 481 APL patients evaluating ATO in first-line therapy during consolidation demonstrated that ATO further reduced the risk of relapse and improved survival as compared to consolidation with daunorubicin/cytarabine. ${ }^{25}$

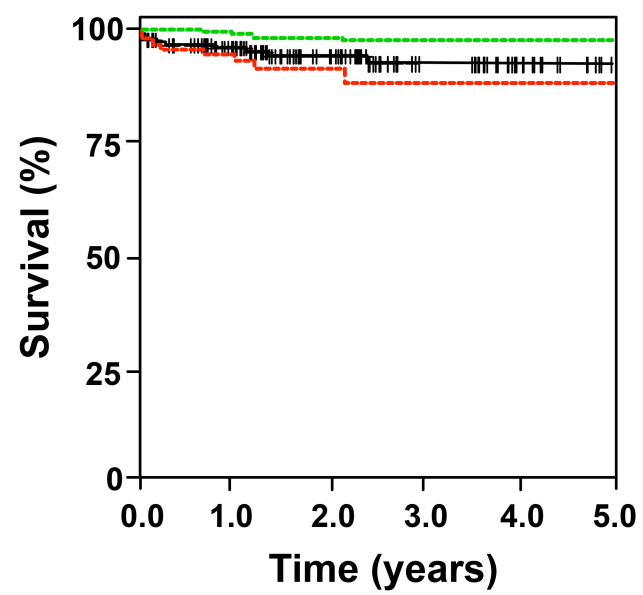

Figure 1. Kaplan Meier plot of overall survival. Green and red curves indicate upper and lower $95 \%$ confidence intervals, respectively.

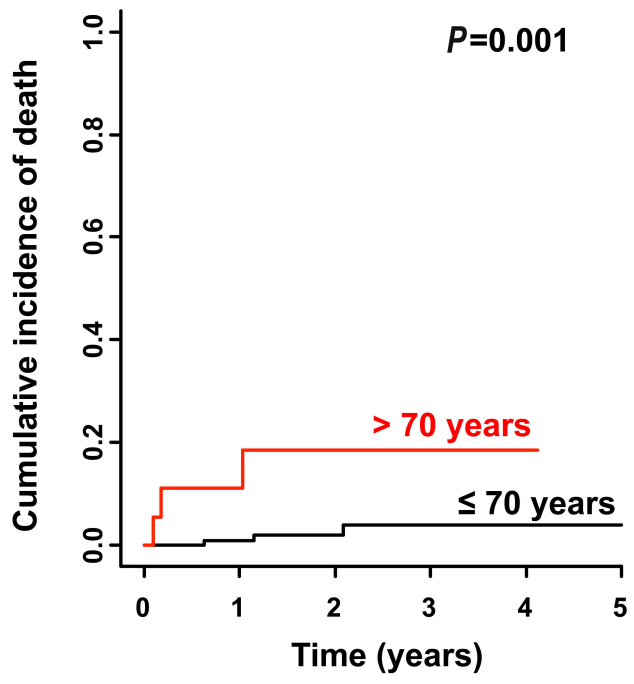

Figure 3. Cumulative incidence of death according to age.
In addition, the randomized phase-III AML17 trial of the UK National Cancer Research Institute Acute Myeloid Leukaemia Working Group showed significantly better event-free survival and relapse-free survival after ATO/ATRA than after the AIDA-based regimen. ${ }^{4}$ In line with previously published results ${ }^{2,3}$ overall survival was excellent in our cohort. In addition, the death rate in remission was also very low at $4 \%$, again arguing for the safety and efficacy of ATO/ATRA as consolidation treatment. In comparison, relatively high rates of deaths in remission, mainly due to infectious complications, were reported with AIDA treatment. ${ }^{20,21}$

Data on measurable residual disease was available for only a subgroup of patients before or after first consolidation $(25 \%)$. Nevertheless, since no relapse was observed, our data as well as the currently up-dated APL recommendations of the European LeukemiaNet suggest that postconsolidation measurable residual disease monitoring can be avoided in this setting and performed only in high-risk patients $\left(\mathrm{WBC}\right.$ count $\left.>10 \times 10^{9} / \mathrm{L}\right)$ in routine clinical practice. $^{18}$

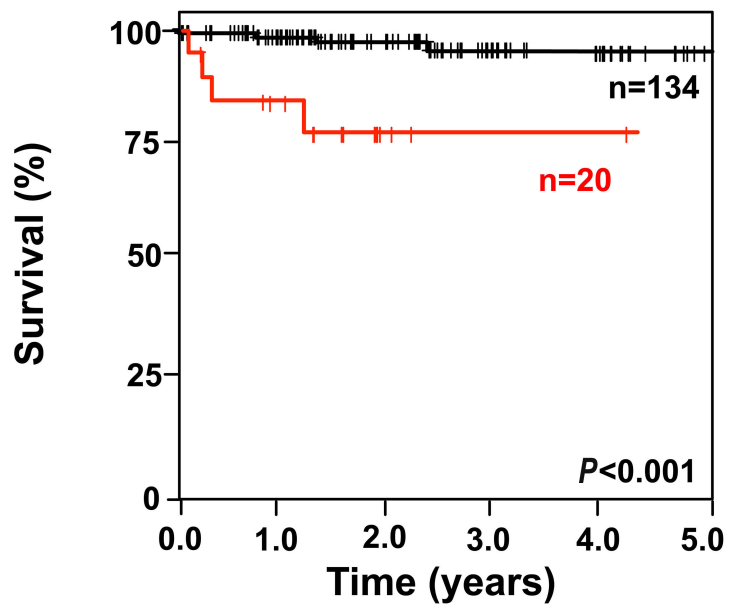

Figure 2. Kaplan Meier plot of overall survival according to age. Red curve indicates age $>70$ years, black curve indicates age $\leq 70$ years.

Table 2. Reported serious adverse events.

\begin{tabular}{lcc} 
Serious adverse events & $\mathbb{N}=\mathbf{1 1 8}$ & $\%$ \\
Infection/sepsis & 31 & 26 \\
Hepatobiliary & 21 & 18 \\
\hline Neurotoxicity/neuropathy & 9 & 8 \\
Differentiation syndrome & 7 & 6 \\
\hline Cardiac, total & 6 & 5 \\
$\quad$ QTc prolongation & 2 & \\
$\quad$ Pericarditis & 1 & \\
$\quad$ Hypertension & 1 & \\
$\quad$ Cardiac decompensation & 1 & \\
$\quad$ Ischemic cardiomyopathy & 1 & 3 \\
Hematologic toxicity & 5 & 3 \\
\hline Hemorrhage/bleeding & 4 & 3 \\
Thromboembolic complications & 4 & 26 \\
\hline Other & 31 & \\
\hline
\end{tabular}

Percentages may not sum up to 100 due to rounding. 
Another positive finding is that none of the patients developed a secondary malignancy after ATO/ATRA, compared to $2 \%$ after chemotherapy, ${ }^{26}$ representing a major improvement in APL treatment, although we acknowledge that the median follow-up time of our cohort is relatively short. However, the reported latency period between the diagnosis of APL and the development of a secondary malignancy of 6.6 months (range, 3.8-7.6 months) as reported by Pagano et al. on behalf of the Gruppo Italiano Malattie Ematologiche dell'Adulto argues strongly for a true lower incidence after ATO/ATRA. ${ }^{27}$ The low relapse rate after ATO-based therapy in our cohort is in line with other reports. $^{2,3,28}$

Confirming our previously published data, ${ }^{29}$ ATO/ATRA was also effective in elderly patients, although age above 70 years was associated with a shorter overall survival and higher cumulative incidence of death in complete remission in comparison with those outcomes in younger patients. Nonetheless, ATO/ATRA should not be withheld in older patients, particularly in light of its high efficacy and safety profile.

The toxicity profiles were comparable to those previously published. ${ }^{2,3}$ The serious adverse events were mainly infections and elevation of liver enzymes. Hepatic toxicity has frequently been reported in studies of ATO, particularly in terms of increased liver enzymes. ${ }^{2,3,30}$ Although frequent, this complication is usually reversible and successfully managed with temporary discontinuation of ATO ${ }^{31}$ Neurological toxicity, mainly consisting of peripheral neuropathy, has also been reported. ${ }^{2,3,30}$ This side effect is usually managed with temporary drug discontinuation. ${ }^{31}$ QTc prolongation is another common side effect of ATO. It can lead to torsade-de-pointes-type ventricular arrhythmia, which is potentially fatal. ${ }^{2}$ However, the reported rate of QTc prolongation was lower than previously published, ${ }^{2-4}$ as was the rate of differentiation syndrome, ${ }^{2-4}$ although the data might be biased due to incomplete reporting. In our series, most of the patients recovered from their serious adverse events, although the outcome was fatal in eight cases.

An unresolved issue is whether or not central nervous system prophylaxis is needed in APL. Pharmacodynamic studies of plasma levels indicated that about one third of ATO crosses the blood-brain barrier, which suggests that a sufficient amount of the drug is available on site to prevent disease recurrence. ${ }^{32}$ In addition, no ATO accumulation or delayed toxicity was observed in patients followed up for over 10 years. ${ }^{34,35}$ However, none of our patients was reported to have central nervous system involvement at diagnosis.
Regarding biological characteristics, additional cytogenetic abnormalities were present in $28 \%$ of the patients, most frequently $\mathrm{t}(15 ; 17)$ within a complex karyotype or trisomy 8 , which is in line with published data. ${ }^{35,36}$ Although data were limited to a small number of patients, FLT3-ITD mutations were less frequent in our cohort than in published data (31\%). ${ }^{37}$ To date, there are still conflicting data regarding the impact of additional chromosomal or genetic abnormalities on outcome in APL patients. ${ }^{38-46}$ In our large cohort, neither the presence of additional cytogenetic abnormalities nor FLT3-ITD had an impact on overall survival, suggesting that ATO/ATRA may abrogate the negative prognostic impact of FLT3ITD. ${ }^{46}$ The latter issue, however, should be interpreted with caution given the limited availability of data on FLT3 mutational status in our cohort.

In conclusion, our real-life data showed excellent and sustained response rates after ATO/ATRA for first-line treatment of APL, confirming published results from the AP0406 trial. ${ }^{2,3}$ Compared to reported historical data, the induction death rate was extremely low despite a high bleeding/hemorrhage rate at diagnosis, probably attributable to improved supportive care and awareness of APL as a medical emergency, but also to early treatment with ATO/ATRA itself. Our results confirm the efficiency and sustainability of ATO/ATRA in the primary management of adults with low-/intermediate-risk APL in the real-life setting, irrespective of their age.

\section{Disclosures}

$U P$ has received research support from TEVA. CT is chief executive officer and co-owner of AgenDix GmbH. All other authors declare that they have no conflicts of interest.

\section{Contributions}

SK and RFS were responsible for the concept of this paper, contributed to the literature search and data collection, analyzed and interpreted data, and wrote the manuscript. UP and LA designed the registry, contributed patients, interpreted data and critically revised the manuscript. DL, MC, KSG, FS, AB, KS-E, PP, YH, $R R, E R, F C, S W K, W E A, S R, R N, C B, M G, E J, P C, K K, C O$, $T B, C S, A A, V K, M W, M d W, D N, C B, C S, J A, A A, S H, A K$, $A R, M G, C W, K S, W H, C M-T, C R, H S, M B, C D B, E L$, and $P F$ contributed patients and critically revised the manuscript. $C T$ performed research and critically revised the manuscript. All authors reviewed and approved the final manuscript.

\section{Acknowledgments}

We acknowledge publication support from Leipzig University.

\section{References}

1. Swerdlow SH, Campo E, Harris NL, et al. WHO Classification of Tumours of Haematopoietic and Lymphoid Tissues. Revised 4th edition. WHO Press, Geneva, Switzerland, 2017.

2.Lo-Coco F, Avvisati G, Vignetti M, et al. Retinoic acid and arsenic trioxide for acute promyelocytic leukemia. N Engl J Med. 2013;369(2):111-121

3. Platzbecker U, Avvisati G, Cicconi L, et al. Improved outcomes with retinoic acid and arsenic trioxide compared with retinoic acid and chemotherapy in non-high-risk acute promyelocytic leukemia: final results of the randomized Italian-German APL0406 trial. J Clin Oncol. 2016;35(6):605-612.

4. Burnett AK, Russell NH, Hills RK, et al Arsenic trioxide and all-trans retinoic acid treatment for acute promyelocytic leukaemia in all risk groups (AML17): results of a randomised, controlled, phase 3 trial. Lancet Oncol. 2015;16(13):1295-1305.

5. Paulson K, Serebrin A, Lambert P, et al. Acute promyelocytic leukaemia is characterized by stable incidence and improved survival that is restricted to patients managed in leukaemia referral centres: a pan-Canadian epidemiological study. Br J Haematol. 2014;166(5):660-666.

6. Park JH, Qiao B, Panageas KS, et al. Early death rate in acute promyelocytic leukemia remains high despite all-trans retinoic acid Blood. 2011;118(5):1248-1254.

7. Rahmé R, Thomas X, Recher C, et al. Early death in acute promyelocytic leukemia (APL) in French centers: a multicenter study in 399 patients. Leukemia. 2014;28(12):24222424

8. Lehmann S, Deneberg S, Antunovic P, et al Early death rates remain high in high-risk APL: update from the Swedish Acute Leukemia Registry 1997-2013. Leukemia. 2017;31(6):1457-1459.

9. Bennett JM, Catovsky D, Daniel MT, et al. Proposed revised criteria for the classification of acute myeloid leukemia. A report of the French-American-British Cooperative Group. Ann Intern Med. 1985;103(4):620-625. 
10. Cheson BD, Bennett JM, Kopecky KJ, et al. Revised recommendations of the International Working Group for Diagnosis, Standardization of Response Criteria, Treatment Outcomes, and Reporting Standards for Therapeutic Trials in Acute Myeloid Leukemia. J Clin Oncol. 2003;21 (24):4642-4649

11. Mitelman F: ISCN: An International System for Human Cytogenetic Nomenclature. Basel, Switzerland: S. Karger; 1995.

12. Yokota S, Kiyoi H, Nakao M, et al. Internal tandem duplication of the FLT3 gene is preferentially seen in acute myeloid leukemia and myelodysplastic syndrome among various hematological malignancies. A study on a large series of patients and cell lines. Leukemia. 1997;11(10):1605-1609.

13. Thiede C, Steudel C, Mohr B, et al. Analysis of FLT3-activating mutations in 979 patients with acute myelogenous leukemia: association with $\mathrm{FAB}$ subtypes and identification of subgroups with poor prognosis. Blood. 2002;99(12):4326-4335

14. Schemper M, Smith TL. A note on quantifying follow-up in studies of failure time. Control Clin Trials. 1996;17(4):343-346.

15. Kaplan E, Meier P. Nonparametric estimation from incomplete observations. J Am Stat Assoc. 1958;53(282):457-481.

16. Gray RJ. A class of k-sample tests for comparing the cumulative incidence of a competing risk. Ann Stat. 1988;16(3):1141-1154.

17. R Development Core Team. R: A language and environment for statistical computing. $R$ Foundation for Statistical Computing. Vienna, Austria, 2014

18. Sanz MA, Fenaux P, Tallman MS, et al. Management of acute promyelocytic leukemia: updated recommendations from an expert panel of the European LeukemiaNet. Blood. 2019;133(15):16301643.

19. Jillella AP, Kota VK. The global problem of early deaths in acute promyelocytic leukemia: a strategy to decrease induction mortality in the most curable leukemia. Blood Rev. 2018;32(2):89-95.

20. Lo-Coco F, Avvisati G, Vignetti M, et al. Front-line treatment of acute promyelocytic leukemia with AIDA induction followed by risk-adapted consolidation for adults younger than 61 years: results of the AIDA2000 trial of the GIMEMA group. Blood. 2010;116(17):3171-3179.

21. de la Serna J, Montesinos P, Vellenga E, et al. Causes and prognostic factors of remission induction failure in patients with acute promyelocytic leukemia treated with alltrans retinoic acid and idarubicin. Blood. 2008;11(7):3395-4302.

22. Testa U, Lo-Coco F. Prognostic factors in acute promyelocytic leukemia: strategies to define high-risk patients. Ann Hematol. 2016;95(5):673-680.
23. Davison K, Mann KK, Miller WH Jr, Davison K. Arsenic trioxide: mechanisms of action. Semin Hematol. 2002;39(2 Suppl 1):3-7.

24. Lo-Coco F, Hasan SK. Understanding the molecular pathogenesis of acute promyelocytic leukemia. Best Pract Res Clin Haematol. 2014;27(1):3-9

25. Powell BL, Moser B, Stock W, et al. Arsenic trioxide improves event-free and overall survival for adults with acute promyelocytic leukemia: North American Leukemia Intergroup Study C9710. Blood. 2010;116 (19):3751-3757

26. Montesinos P, González JD, González J, et al. Therapy-related myeloid neoplasms in patients with acute promyelocytic leukemia treated with all-trans-retinoic acid and anthracycline-based chemotherapy. J Clin Oncol. 2010;28(24):3872-3879.

27. Pagano L, Pulsoni A. Second malignancy after treatment of acute promyelocytic leukemia: experience of GIMEMA trials. Blood. 2002;100(4):1514-1515.

28. Zhang Y, Zhang Z, Li J, et al. Long-term efficacy and safety of arsenic trioxide for firstline treatment of elderly patients with newly diagnosed acute promyelocytic leukemia. Cancer. 2013;119(1):115-125

29. Kayser S, Rahmé R, Martínez-Cuadrón D, et al. Outcome of older (70 years) APL patients frontline treated with or without arsenic trioxide-an International Collaborative Study. Leukemia. 2020;34(9):2333-2341.

30. Ghavamzadeh A, Alimoghaddam K Rostami S, et al. Phase II study of singleagent arsenic trioxide for the front-line therapy of acute promyelocytic leukemia. J Clin Oncol. 2011;29(20):2753-2757.

31. Kayser S, Schlenk RF, Platzbecker U. Management of patients with acute promyelocytic leukemia. Leukemia. 2018;32 (6):1277-1294.

32. Kiguchi T, Yoshino Y, Yuan B, et al Speciation of arsenic trioxide penetrates into cerebrospinal fluid in patients with acute promyelocytic leukemia. Leuk Res. 2010;34 (3):403-405

33. Hu J, Liu YF, Wu CF, et al. Long-term efficacy and safety of all-trans retinoic acid/arsenic trioxide-based therapy in newly diagnosed acute promyelocytic leukemia. Proc Natl Acad Sci U S A. 2009;106(9):3342-3347.

34. Zhu H, Hu J, Chen L, et al. The 12-year follow-up of survival, chronic adverse effects, and retention of arsenic in patients with acute promyelocytic leukemia. Blood. 2016;128(11):1525-1528.

35. Schlenk RF, Germing U, Hartmann F, et al. High-dose cytarabine and mitoxantrone in consolidation therapy for acute promyelocytic leukemia. Leukemia. 2005;19(6):978983.

36. Lou Y, Suo S, Tong H, et al. Characteristics and prognosis analysis of additional chromosome abnormalities in newly diagnosed acute promyelocytic leukemia treated with arsenic trioxide as the front-line therapy. Leuk Res. 2013;37(11):1451-1456.

37. Noguera NI, Catalano G, Banella C, et al Acute promyelocytic leukemia: update on the mechanisms of leukemogenesis, resistance and on innovative treatment strategies. Cancers. 2019;18;11(10):1591

38. Kiyoi H, Naoe T, Yokota S, et al. Internal tandem duplication of FLT3 associated with leukocytosis in acute promyelocytic leukemia. Leukemia Study Group of the Ministry of Health and Welfare (Kohseisho). Leukemia. 1997;11(9):1447-1452.

39. Noguera NI, Breccia M, Divona M, et al Alterations of the FLT3 gene in acute promyelocytic leukemia: association with diagnostic characteristics and analysis of clinical outcome in patients treated with the Italian AIDA protocol. Leukemia. 2002;16 (11):2185-2189.

40. Shih LY, Kuo MC, Liang DC, et al. Internal tandem duplication and Asp835 mutations of the FMS-like tyrosine kinase 3 (FLT3) gene in acute promyelocytic leukemia. Cancer. 2003;98(6):1206-1216.

41. Lucena-Araujo AR, Kim HT, Jacomo RH, et al. Internal tandem duplication of the FLT3 gene confers poor overall survival in patients with acute promyelocytic leukemia treated with all-trans retinoic acid and anthracycline-based chemotherapy: an International Consortium on Acute Promyelocytic Leukemia study. Ann Hematol. 2014;93(12): 2001-2010.

42. De Botton S, Chevret S, Sanz M, et al. Additional chromosomal abnormalities in patients with acute promyelocytic leukaemia (APL) do not confer poor prognosis: results of APL 93 trial. Br J Haematol. 2000;111(3):801-806.

43. Cervera J, Montesinos P, Hernández-Rivas JM, et al. Additional chromosome abnormalities in patients with acute promyelocytic leukemia treated with all-trans retinoic acid and chemotherapy. Haematologica. 2010;95(3):424-431.

44. Pantic M, Novak A, Marisavljevic D, et al Additional chromosome aberrations in acute promyelocytic leukemia: characteristics and prognostic influence. Med Oncol. 2000;17(4):307-313

45. Poiré X, Moser BK, Gallagher RE, et al. Arsenic trioxide in front-line therapy of acute promyelocytic leukemia (C9710): prognostic significance of FLT3 mutations and complex karyotype. Leuk Lymphoma. 2014;55(7):1523-1532

46. Cicconi L, Divona M, Ciardi C, et al. PMLRAR $\alpha$ kinetics and impact of FLT3-ITD mutations in newly diagnosed acute promyelocytic leukaemia treated with ATRA and ATO or ATRA and chemotherapy. Leukemia. 2016;30(10):1987-1992. 